\title{
Desenvolvimento e produção da carobinha (Jacaranda decurrens Cham. subsp. symmetrifoliolata Farias \& Proença) cultivada sob dois arranjos de plantas, com ou sem cobertura de cama-de-frango no solo
}

SANGALLI, A. ${ }^{\text {* }}$; VIEIRA, M.C. ${ }^{2}$; HEREDIAZÁRATE, N.A. ${ }^{2}$; SCALON, S.P.Q. ${ }^{2}$

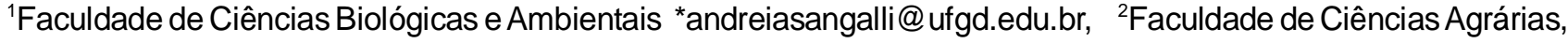
Universidade Federal da Grande Dourados-UFGD, CEP: 79.804-970, Dourados-Brasil

RESUMO: O objetivo deste trabalho foi avaliar o desenvolvimento e a produção da carobinha (Jacaranda decurrens subsp. symmetrifoliolata) cultivada ex situ sob dois arranjos de plantas, sem ou com cama-de-frango semidecomposta. O trabalho foi desenvolvido sob condições de campo, no Horto de Plantas Medicinais (HPM), da Universidade Federal da Grande Dourados (UFGD) em solo tipo Latossolo Vermelho distroférrico. Estudaram-se os arranjos em fileiras simples e duplas e o uso ou não de cama-de-frango de corte semidecomposta em cobertura, dispostos como fatorial $2 \times 2$, no delineamento experimental de blocos casualizados, com seis repetições. As maiores alturas máximas das plantas $\left(61,3 \mathrm{~cm}\right.$ planta-1 $\left.^{-1}\right)$ aos 555 dias após 0 transplante foram daquelas cultivadas sob fileira dupla com cama-de-frango. Os números médios de folhas e de ramificações por planta ao longo do ciclo foram de onze e duas, respectivamente. O diâmetro médio do caule de plantas cultivadas em fileiras simples foi de $8,3 \mathrm{~mm}$, enquanto sob fileiras duplas, foi de 10,8 mm, ambos aos 552 dias de ciclo. As características avaliadas, na colheita, aos 555 dias após o transplante não foram influenciadas pela interação entre arranjos de plantas e o uso da cama-de-frango nem pelos fatores isoladamente. Dessa forma, concluiu-se que o cultivo em fileiras duplas foi favorável à produtividade da carobinha, por possibilitar maior produção por área.

Palavras-chave: plantas medicinais, planta nativa, cultivo ex situ

\begin{abstract}
Development and yield of "carobinha" (Jacaranda decurrens Cham. subsp. symmetrifoliolata Farias \& Proença) cultivated under two plant arrangements, with or without chicken manure covering on the soil. The aim of this study was to evaluate the development and yield of "carobinha" (Jacaranda decurrens subsp. symmetrifoliolata) cultivated ex situ under two plant arrangements, with or without semi-decomposed chicken manure. This study was carried out under field conditions at the Medicinal Plant Garden (HPM), Federal University of Grande Dourados (UFGD), in Distroferric Red Latossol. Arrangements with simple and double rows and the use or not of semi-decomposed chicken manure as covering were studied as $2 \times 2$ factorial arrangement in a randomized block experimental design, with six replicates. The highest maximum heights $\left(61.3 \mathrm{~cm}\right.$ plant $\left.{ }^{-1}\right)$ at 555 days after transplant were obtained by plants cultivated under double rows with chicken manure. The mean numbers of leaves and branches per plant during the cycle were eleven and two, respectively. The mean stem diameter of plants that were cultivated in simple rows was $8.3 \mathrm{~mm}$, while that of plants cultivated in double rows was $10.8 \mathrm{~mm}$, both at 552 days of the cycle. The evaluated characteristics, in the harvest at 555 days after transplant, were not influenced by the interaction between plant arrangements and use of chicken manure or by factors in an isolated way. Thus, cultivation in double rows was favorable to "carobinha" yield for allowing the highest yield per area.
\end{abstract}

Key words: medicinal plant, native plant, ex situ cultivation

Recebido para publicação em 15/09/2009

Aceito para publicação em 22/04/2011

Rev. Bras. PI. Med., Botucatu, v.13, n.4, p.439-446, 2011. 


\section{INTRODUÇÃO}

A intensa exploração antrópica dos solos do Cerrado, como consequência da utilização maciça de insumos tecnológicos, justifica estudos permanentes no sentido de maximizar os benefícios e minimizar os impactos negativos da intervenção humana nesse bioma (Silva et al., 2006). Outra característica que deve ser destacada é a heterogeneidade da distribuição de sua vegetação, havendo espécies endêmicas dos Cerrados da região Norte, outras do Centro-Oeste e outras do Sudeste (Coutinho, 2002).

As espécies nativas, na maioria, apresentam possibilidade de múltiplos usos, além de reunirem características favoráveis de adaptação às condições do ambiente. No entanto, ainda são escassos os estudos relativos a essas espécies com intuito de conhecer o crescimento e a produção em condições de cultivo ex situ, como acontece com Jacaranda decurrens subsp. symmetrifoliolata (carobinha). Isso tem acarretado dificuldades na utilização, seja como opções de uso econômico (medicinal) ou como forma de recomposição e recuperação de áreas devastadas (Silva et al., 2006).

Jacaranda decurrens subsp. symmetrifoliolata (Bignoniaceae) - subarbusto presente em diversas fisionomias do Cerrado brasileiro, é popularmente descrita como planta medicinal (Farias \& Proença, 2003) e o uso indiscriminado do sistema radicular no preparo de chás caseiros como depurativo do sangue e cicatrizante de feridas uterinas e dos ovários (Sangalli et al., 2002) tem restringido o habitat da carobinha. Estudos químicos realizados com a carobinha demonstraram que as raízes e as folhas são fontes ricas em antioxidantes, que os teores de fenóis das folhas e raízes são similares, e que os valores de flavonóides das folhas são superiores aos das raízes (Medina et al., 2008). Embora de grande importância pelas propriedades medicinais e constituição química, a espécie é pouco estudada quanto à adaptação do crescimento ex situ.

As medidas de crescimento de uma espécie permitem estudar a capacidade de adaptar-se às condições climáticas no local onde é cultivada, sendo possível avaliá-la sem comprometer a vida do vegetal, por meio de medidas de comprimento e diâmetro dos indivíduos ou dos órgãos (Santos et al., 2004). Espécies vegetais podem desenvolver mecanismos eficientes de manutenção do metabolismo, para garantir a sobrevivência em ambientes adversos (Leitão \& Silva, 2004).

É importante ressaltar que essa capacidade de adaptação também é dependente da nutrição do solo de cultivo. Santos \& Coelho (2008) comentam que a matéria orgânica pode e deve ser conservada mediante a prática da adubação orgânica que estará funcionando como armazém de nutrientes para a planta, liberando-os gradualmente para o uso da cultura e melhorando as propriedades físicas do solo.

A prática da adubação orgânica proporciona melhoria da estrutura física do solo, aumenta a retenção de água, diminui perdas por erosão, favorece o controle biológico devido à maior população microbiana e melhora a capacidade tampão do solo. Além disso, por possuir na composição, os macros e micronutrientes em quantidades bem equilibradas, possibilita às plantas os absorverem conforme a necessidade, em quantidade e qualidade (Kiehl, 2008).

Dentre os adubos orgânicos empregados, merece destaque a cama-de-frango, que normalmente apresenta elevados teores de nutrientes (Oliveira et al., 2008). Apesar da importância, nenhum trabalho foi encontrado na bibliografia consultada sobre uso desse tipo de adubação orgânica em plantas nativas do Cerrado.

De acordo com Carvalho (1997), existe variação de crescimento entre espécies, assim como pode haver variação dentro da mesma espécie e entre indivíduos por causa das diferenças que existem entre tamanhos e grau de iluminação do dossel e a influência dos fatores genéticos.

Guerreiro et al. (2006) estudaram a produção de biomassa de partes subterrâneas e aéreas da Jacaranda decurrens, em quatro períodos (290, 380, 470 e 560 dias após a emergência - DAE) visando estabelecer o melhor momento da colheita. A maior produção de massa seca de raízes $(5,54 \mathrm{~g})$ e da parte aérea $(3,79 \mathrm{~g})$ ocorreu aos $560 \mathrm{DAE}$.

O objetivo deste trabalho foi avaliar o desenvolvimento e a produção da carobinha cultivada ex situ sob dois arranjos de plantas, sem ou com camade-frango semidecomposta.

\section{MATERIAL E MÉTODO}

O trabalho foi desenvolvido sob condições de campo, no Horto de Plantas Medicinais (HPM), da Universidade Federal da Grande Dourados (UFGD), no período de julho de 2005 a maio de 2007. O HPM tem como coordenadas geográficas 22¹1'43.7"de latitude Sul e 54⒌'08.5" de longitude Oeste. A altitude da área é de $452 \mathrm{~m}$ e o clima é classificado como Cwa Mesotérmico Úmido, com precipitação e temperatura média anuais de $1500 \mathrm{~mm}$ e $22^{\circ} \mathrm{C}$, respectivamente. As temperaturas máximas e mínimas e as precipitações no período do cultivo encontram-se na Figura 1.

O solo do HPM é do tipo Latossolo Vermelho distroférrico e o resultado das análises químicas foi: $\mathrm{pH} \mathrm{H} \mathrm{O}(1: 2,5)=5,3 ; \mathrm{P}\left(\mathrm{mg} \mathrm{dm}^{-3}\right)=24,0$ (extrator Mehlich-1, conforme Braga \& Defelipo, 1974); K $\left(\mathrm{mmol}_{\mathrm{c}} \cdot \mathrm{dm}^{-3}\right)=6,6 ; \mathrm{Al}^{+3}\left(\mathrm{mmol}_{\mathrm{c}} \mathrm{dm}^{-3}\right)=3,1 ; \mathrm{Ca}^{+2}\left(\mathrm{mmol}_{\mathrm{c}}\right.$ $\left.\mathrm{dm}^{-3}\right)=44,9 ; \mathrm{Mg}\left(\mathrm{mmol}_{\mathrm{c}} \mathrm{dm}^{-3}\right)=13,0 ; \mathrm{H}+\mathrm{Al}\left(\mathrm{mmol}_{\mathrm{c}}\right.$ $\left.\mathrm{dm}^{-3}\right)=69,0 ; \mathrm{SB}\left(\mathrm{mmol}_{\mathrm{c}} \mathrm{dm}^{-3}\right)=64,5 ; \mathrm{CTC}\left(\mathrm{mmol}_{\mathrm{c}} \mathrm{dm}^{-3}\right)$ $=133,5 ; \mathrm{V}(\%)=48,0$ e $\mathrm{MO}\left(\mathrm{g} \mathrm{kg}^{-1}\right)=34,7$. 


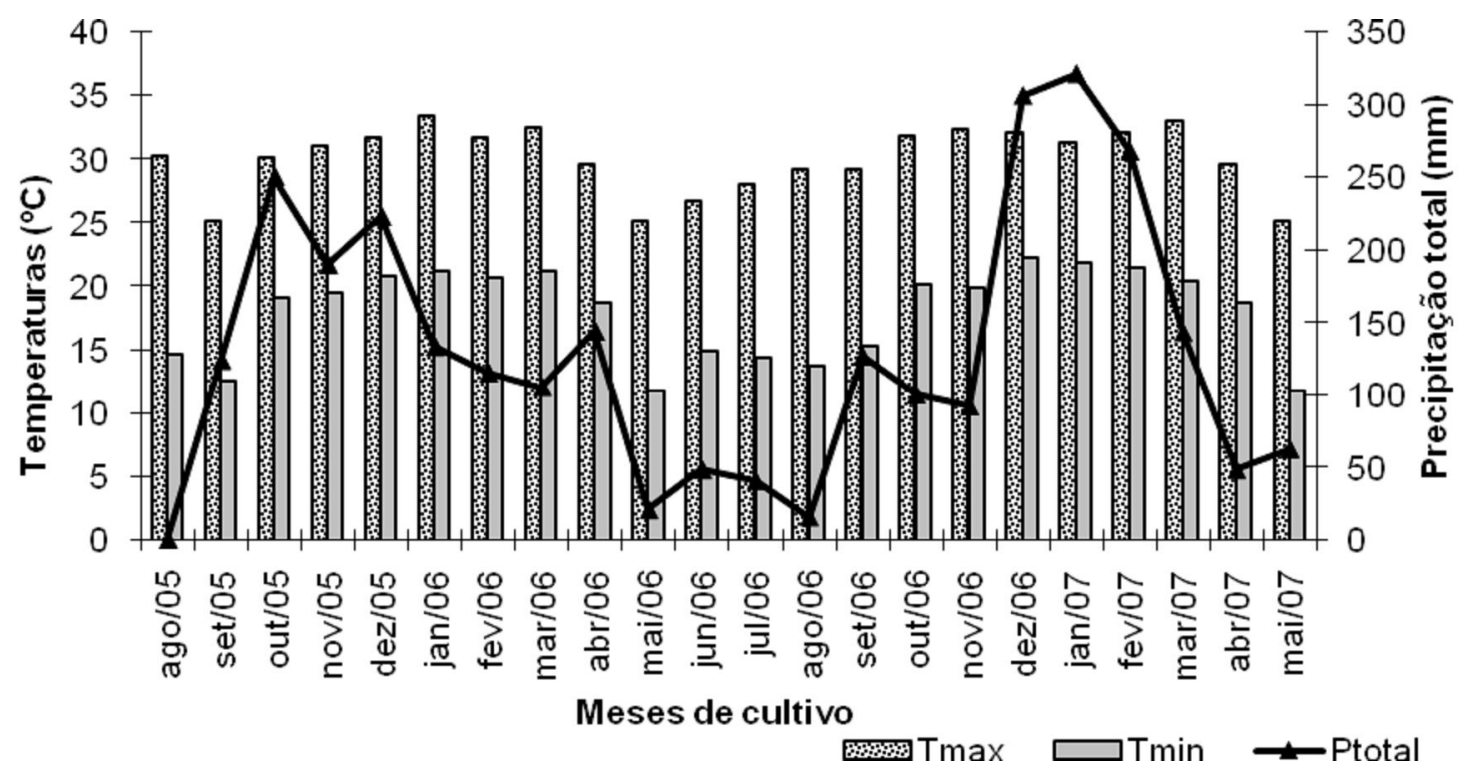

FIGURA 1. Temperaturas máxima e mínima e precipitação total durante os meses de cultivo da Jacaranda decurrens subsp. symmetrifoliolata. UFGD, Dourados, MS, 2008.

As características químicas do local de origem da planta, a Fazenda Lagoa Azul, localizada à margem direita da Rodovia BR 270, Km 70, Dourados a Itahum, com vegetação característica de Cerrado, foram $\mathrm{pH} \mathrm{H}_{2} \mathrm{O}(1: 2,5)=5,1 ; \mathrm{P}\left(\mathrm{mg} \mathrm{dm}^{-3}\right)=2,0$ (extrator Mehlich-1, conforme Braga \& Defelipo, 1974); $\mathrm{K}\left(\mathrm{mmol}_{\mathrm{c}}\right.$ $\left.\mathrm{dm}^{-3}\right)=0,2 ; \mathrm{Al}^{+3}\left(\mathrm{mmol}_{\mathrm{c}} \mathrm{dm}^{-3}\right)=6,1 ; \mathrm{Ca}^{+2}\left(\mathrm{mmol}_{\mathrm{c}} \mathrm{dm}^{-3}\right)$ $=0,7 ; \mathrm{Mg}\left(\mathrm{mmol}_{\mathrm{c}} \mathrm{dm}^{-3}\right)=0,5 ; \mathrm{H}+\mathrm{Al}\left(\mathrm{mmol}_{\mathrm{c}} \mathrm{dm}^{-3}\right)=$ 33,0; SB $\left(\mathrm{mmol}_{\mathrm{cm}} \mathrm{dm}^{-3}\right)=0,9 ; \mathrm{CTC}\left(\mathrm{mmol}_{\mathrm{c}} \mathrm{dm}^{-3}\right)=33,9$; $\mathrm{V}(\%)=2,0$ e $\mathrm{MO}\left(\mathrm{g} \mathrm{kg}^{-1}\right)=5,8$. A análise granulométrica do solo de origem apresentou $17,3 \%$ de argila, 1,5\% de silte, $36,7 \%$ de areia grossa e $44,5 \%$ de areia fina.

Foram estudados 0 arranjo das plantas em fileiras simples ou dupla e o uso ou não de cobertura do solo com cama-de-frango semidecomposta, na dose de $10 \mathrm{t} \mathrm{ha}^{-1}$. Os tratamentos foram dispostos como fatorial $2 \times 2$, no delineamento experimental blocos casualizados, com seis repetições. Cada parcela foi composta por um canteiro de $1,50 \mathrm{~m}$ de largura total e 1,00 m de largura útil por 2,40 m de comprimento, com uma ou duas fileiras de plantas espaçadas de 0,60 $\mathrm{m}$ e 0,40 $\mathrm{m}$ entre plantas.

Para a propagação da carobinha foram utilizadas sementes de frutos colhidos em plantas cultivadas no HPM, formadas a partir de sementes de frutos de plantas nativas da Fazenda Lagoa Azul. O semeio foi feito em bandejas de poliestireno com 72 células, usando substrato Plantmax®. O início da emergência ocorreu aproximadamente 40 dias após 0 semeio. As mudas foram transplantadas para o local definitivo quando apresentavam altura aproximada de $5,0 \mathrm{~cm}$ e cinco folhas verdadeiras, aos 90 dias após o semeio. Foram abertos sulcos sobre os canteiros e as mudas enterradas até o coleto. A cama-de-frango foi distribuída sobre o solo, imediatamente após o transplante, nas parcelas correspondentes. Não foi realizada nenhuma adubação mineral. Durante o ciclo de cultivo, os tratos culturais compreenderam irrigações por aspersão, com turnos de rega a cada dois a três dias, visando manter o solo com $70 \%$ da capacidade de campo. O controle das plantas daninhas foi com o uso de enxada.

Durante o ciclo de cultivo, desde os 60 até 555 dias após o transplante - DAT, a cada 45 dias, foram medidas as características de todas as plantas das parcelas, como a altura das plantas (cm) - com o auxílio da régua graduada, desde o nível do solo até a inflexão da folha mais alta; número de folhas; diâmetro do caule $(\mathrm{mm})$, medido com paquímetro digital, a aproximadamente $1,0 \mathrm{~cm}$ acima do solo e número de ramificações.

Aos 555 DAT foram colhidas duas plantas competitivas por parcela, as quais foram arrancadas inteiras. A coleta do sistema subterrâneo foi realizada com o auxílio de pá reta, cavando-se 1,50 m de profundidade. Posteriormente, avaliaram-se: massas frescas e secas do sistema subterrâneo e parte aérea. A massa seca foi obtida após a secagem em estufa de circulação de ar forçada a $60^{\circ} \pm 2^{\circ} \mathrm{C}$, até massa constante; área foliar $\left(\mathrm{cm}^{2}\right)$, determinada com o integrador foliar LICOR 3000; diâmetro da raiz (mm), medido com paquímetro, a aproximadamente $1 \mathrm{~cm}$ abaixo do coleto e comprimento da maior raiz $(\mathrm{cm})$, medido a partir do coleto até o ápice.

Os dados foram submetidos à análise de variância e quando detectou-se significância pelo teste $F$, as médias em função de dias após o transplante foram submetidas à análise de regressão, ambos a 
$5 \%$ de probabilidade (Ribeiro Júnior., 2001; PimentelGomes \& Garcia, 2002). Os dados que não se ajustaram às equações testadas, foram apresentados em sua forma original.

\section{RESULTADO E DISCUSSÃO}

Houve interação significativa entre fileiras e cama-de-frango para a altura de plantas, que apresentou crescimento linear independente da forma de cultivo. As alturas máximas para as plantas cultivadas em fileira simples em solo sem e com cobertura de cama-defrango, respectivamente, foram de $54,5 \mathrm{~cm}_{\text {planta- }}{ }^{-1} \mathrm{e}$ $60,7 \mathrm{~cm}$ planta- $^{-1}$, aos 555 dias após o transplante (Figura 2A). Quando cultivadas em fileiras duplas, a altura das plantas cultivadas em solo sem ou com a cama-defrango, foram de $59,1 \mathrm{~cm}$ planta-1 $^{-1}$ e $61,3 \mathrm{~cm}_{\text {planta }}{ }^{-1}$, respectivamente, após 555 do transplante (Figura 2B). A maior altura das plantas com o uso da cama-de-frango deve-se, provavelmente, à ação que ela deve ter exercido

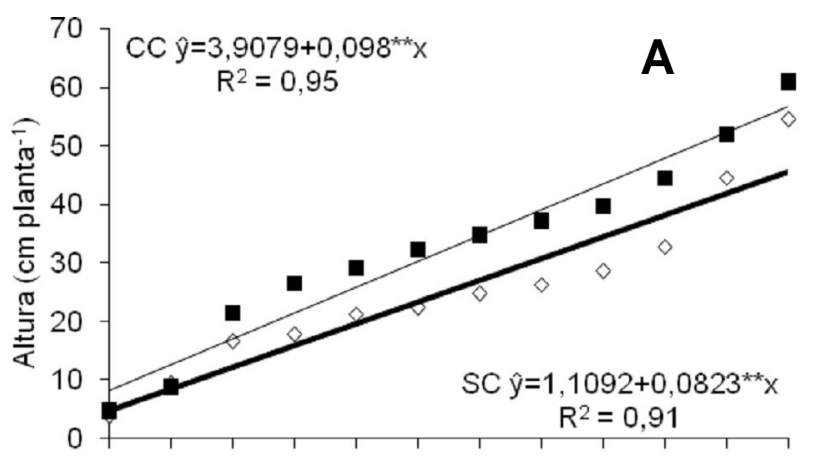

60105150195240285330375420465510555

Dias após o transplante $\diamond S C \square C C$ para favorecer a manutenção da umidade do solo e dos nutrientes disponíveis e com isso pode ter melhorado o desenvolvimento do sistema radicular das plantas (Kiehl, 2008).

$\mathrm{O}$ fato de as maiores alturas terem sido registradas no cultivo em fileira dupla é um indicativo de que para a carobinha o maior adensamento entre plantas não afeta seu desenvolvimento. Esse comportamento pode ser um reflexo do que ocorre com a espécie in situ, em que as plantas geralmente se desenvolvem em reboleira ou próximas a outras espécies, aproveitando-se da sombra que formam. Larcher (2000) ressalta que a densidade de plantio favorece a produtividade de diversas espécies, e os sistemas vegetais apresentam mecanismos de auto-regulação baseando-se na capacidade de adaptação do organismo individual ou das populações, e no equilíbrio das relações de interferência como competição por nutrientes, água e luz, que influencia na produção e partição dos fotoassimilados (Taiz \& Zeiger, 2004).

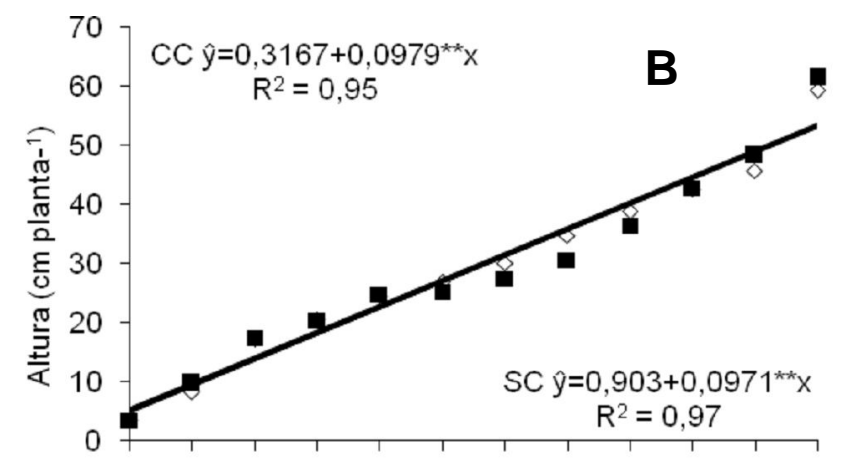

60105150195240285330375420465510555

Dias após o transplante $\diamond \mathrm{SC} \boxminus \mathrm{CC}$

FIGURA 2. Altura da Jacaranda decurrens subsp. symmetrifoliolata em função A) de fileiras simples e B) de fileiras duplas, sem (SC) ou com (CC) cobertura do solo com cama-de-frango. UFGD, Dourados, MS, 2008. C.V. $(\%)=$ 25,5 ( ${ }^{*} \%$ de probabilidade).

O número de folhas foi influenciado significativamente pela interação arranjo de plantas e cama-de-frango (Figuras 3A e 3B). O decréscimo acentuado no número de folhas que foi observado entre 180 e 300 dias após o transplante - DAT mostra que as plantas de carobinha tiveram uma fase de deciduidade dependente das condições do ambiente das estações outono-inverno, quando as precipitações e temperaturas foram inferiores às das demais estações (Figura 1).

As maiores perdas de folhas ocorreram nos tratamentos onde se fez cobertura do solo com camade-frango, tanto no cultivo com uma quanto com duas fileiras de plantas no canteiro. Nesse período, a fase de queda das folhas foi seguida pela fase reprodutiva, quando ocorreu o desenvolvimento acentuado de inflorescências, aos 380 dias do transplante. Ao final da abertura dos botões florais, o que ocorreu após 390 DAT, iniciou-se a fase da rebrota vegetativa, de forma geral, após os 428 dias (Figuras 3A e 3B), período coincidente com o início da primavera, quando as precipitações tenderam a ser mais abundantes e as temperaturas mais elevadas (Figura 1).

Segundo Larcher (2000), o início e a duração das distintas fases de desenvolvimento das plantas variam de um ano para o outro, dependendo das condições climáticas. Os fatores ambientais, como água e luz, em conjunto com a regulação endógena influenciam a formação das flores, resultando em competição entre as fases reprodutiva e vegetativa, pois o vegetal remove as reservas que poderiam ser usadas na produção de gemas e investe nas gemas florais. Sangalli et al. (2002) constataram o comportamento decíduo da carobinha na área nativa, sugerindo ser essa uma característica determinada geneticamente pela espécie. 


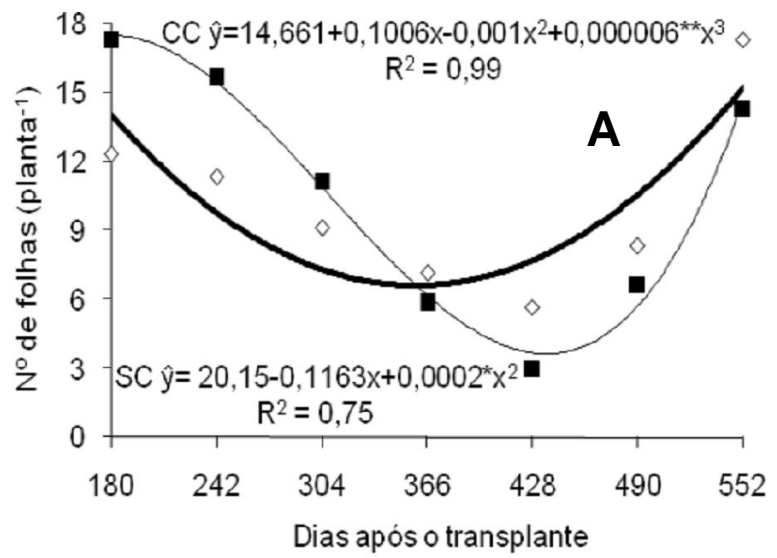

$\diamond \mathrm{SC} \quad \mathbf{\mathrm { CCC }}$

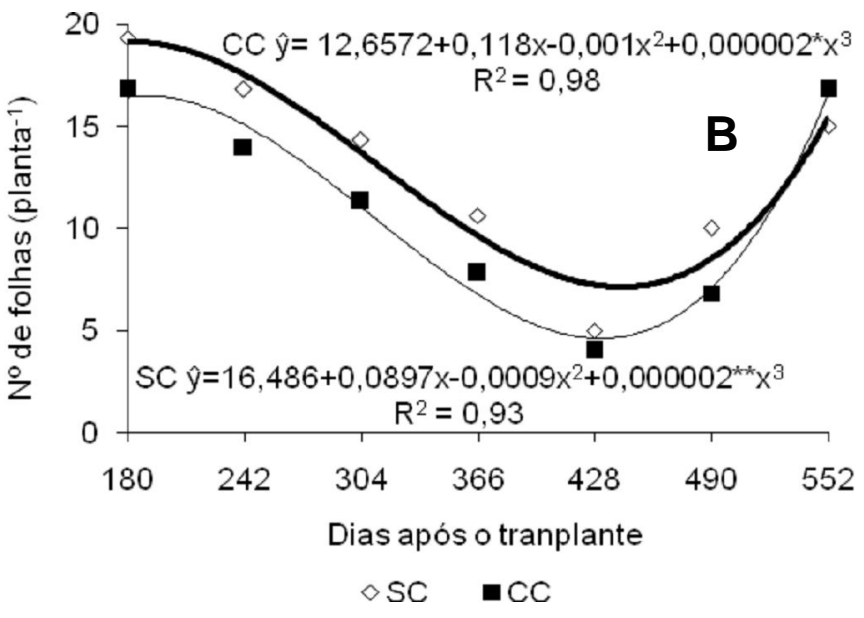

FIGURA 3. Número de folhas de Jacaranda decurrens subsp. symmetrifoliolata em função A) de fileiras simples e B) de fileiras duplas, sem (SC) ou com (CC) cobertura do solo com cama-de-frango. UFGD, Dourados, MS, 2008. C.V. $(\%)=35,1\left({ }^{*} 5 \%\right.$ de probabilidade $)$.

O diâmetro do caule foi influenciado pelo arranjo de plantas, mas não pelo uso da cama-defrango. Aos 552 dias de ciclo, as plantas cultivadas em fileiras simples apresentaram diâmetro médio de $8,3 \mathrm{~mm}$ planta-1 enquanto aquelas sob fileiras duplas apresentaram 10,8 $\mathrm{mm}$ planta $^{-1}$ (Figura 4). O aumento do crescimento do caule, a partir de 490 dias, deve ser associado ao fato de as plantas, quando em estádios de desenvolvimento vegetativo, crescerem rapidamente tanto em extensão como em diâmetro. Esse comportamento também pode estar associado à retomada de distribuição de fotoassimilados para as diferentes partes do vegetal uma vez que o aumento do diâmetro ocorreu no período da rebrota, em que os frutos já estavam formados, estando a energia disponível para o crescimento vegetativo.
Segundo Taiz \& Zeiger (2004), a distribuição diferencial de fotoassimilados na planta determina os padrões de crescimento, que deve ser equilibrado entre a parte aérea, responsável pela produtividade fotossintética, e a raiz, que é a principal fonte de absorção de água e minerais. Logo, para o desenvolvimento harmônico da planta, cada órgão deve receber a quantidade necessária de assimilados e esse abastecimento deve ser efetuado no tempo certo, o que é determinado geneticamente pelo vegetal (Larcher, 2000).

O número de ramificações foi variável durante o período de avaliação da carobinha, sendo a média de 2,0 planta $^{-1}$, independente do cultivo em fileiras simples ou duplas e do uso ou não da cama-de-frango (Figura 5). A capacidade de produzir novas

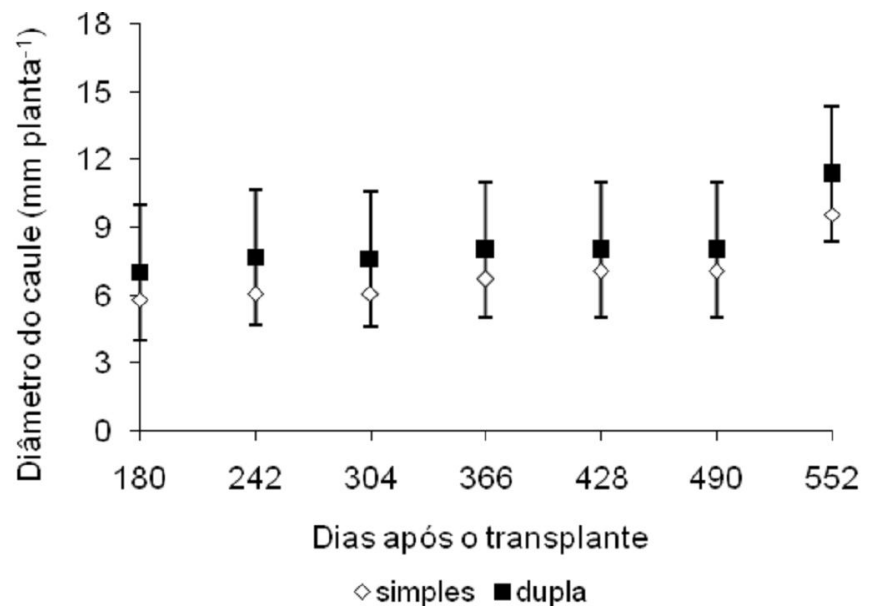

FIGURA 4. Diâmetro do caule da Jacaranda decurrens subsp. symmetrifoliolata em função do cultivo em fileiras simples ou duplas. Dados em função de cama foram agrupados. UFGD, Dourados, MS, 2008. C.V. $(\%)=30,1\left({ }^{*} 5 \%\right.$ de probabilidade). 


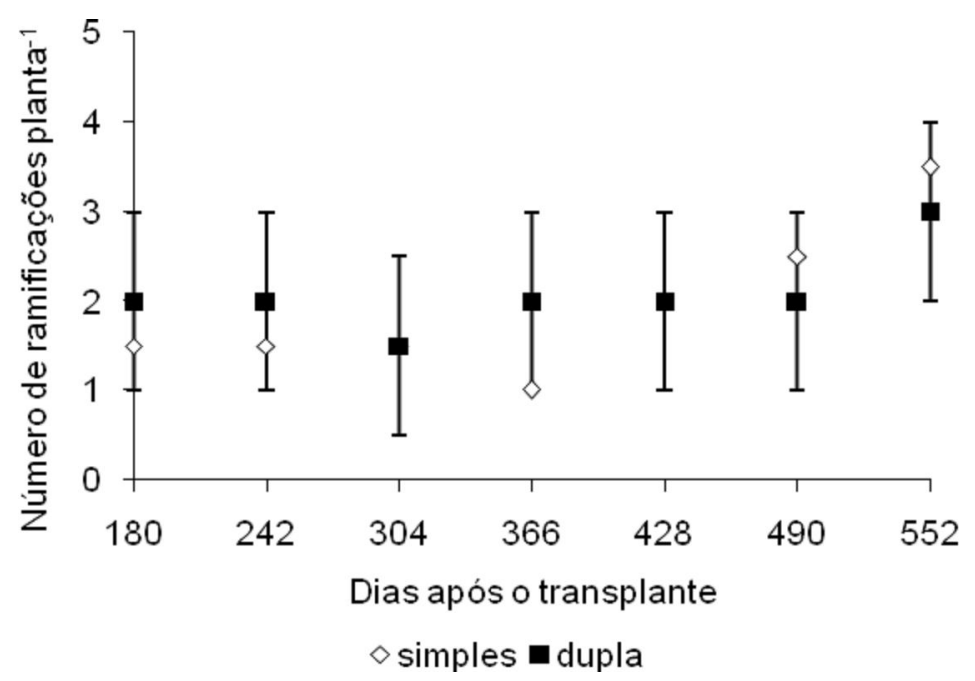

FIGURA 5. Número de ramificações em Jacaranda decurrens subsp. symmetrifoliolata em função do cultivo em fileiras simples ou duplas. Dados em função de cama foram agrupados. UFGD, Dourados, MS, 2008. C.V.(\%) = $60,2\left({ }^{*} 5 \%\right.$ de probabilidade).

ramificações junto à base do caule, a partir de 366 dias para as plantas sob fileiras simples e a partir de 490 dias para as plantas sob fileiras duplas, indica a presença de rebrota da espécie, fato também constatado após a deciduidade foliar, e que permite que ocorra a regeneração dos indivíduos.

Borges (2002), trabalhando com Heteropterys aphrodisiacaO. Mach. (nó-de-cachorro), espécie nativa do Cerrado, destacou a rebrota como sendo uma fase que aumenta a probabilidade de sobrevivência de vegetais comercialmente importantes, como os utilizados na medicina popular e que habitam áreas de intensa intervenção humana.

As massas frescas e secas das partes aéreas e do sistema subterrâneo foram influenciadas significativamente pelo arranjo de plantas. O cultivo em fileiras duplas resultou nas maiores produtividades de massa fresca e seca da parte aérea e do sistema subterrâneo (Tabela 1). As produções de massa fresca e seca da parte aérea foram superiores em $3137,3 \mathrm{~kg}$ ha $^{-1}(63,3 \%)$ e $1669,1 \mathrm{~kg} \mathrm{ha}^{-1}(65,2 \%)$, respectivamente, e de massa fresca e seca do sistema subterrâneo em $3626,7 \mathrm{~kg} \mathrm{ha}^{-1}(60 \%)$ e $1850,4 \mathrm{~kg} \mathrm{ha}^{-1}(62,0 \%)$, respectivamente, para as plantas cultivadas no arranjo de fileiras duplas em relação a fileiras simples.

Deve-se ressaltar ainda que as massas frescas e secas do sistema subterrâneo foram maiores do que as massas frescas e secas da parte aérea (Tabela 1). Esse fato parece ser característico de plantas nativas do Cerrado, que investem mais energia no sistema radicular, o que é comprovado pela relação sistema subterrâneo/parte aérea registrada para a carobinha (Tabela 1). Maior desenvolvimento do sistema radicular em comparação ao crescimento da parte aérea também foi constatado em mangabeira (Hancornia speciosa Gomez) em diferentes substratos por Rosa et al. (2005) e em cagaita (Eugenia dysenterica DC.) por Souza et al. (2000), espécies nativas de Cerrado.

A área foliar, o diâmetro e o comprimento da maior raiz, na colheita, não foram influenciados pela interação entre arranjos de plantas e o uso da camade-frango (Tabela 1) nem pelos fatores isoladamente. Este resultado deveu-se, provavelmente, ao alto coeficiente de variação das características avaliadas, demonstrando que houve grande variabilidade genética intra-populacional. Fato semelhante foi constatado em populações nativas de Anemopaegma arvense (Vell.) Stellf. (catuaba) por Batistini (2006) e em Solanum lycocarpum St. Hil. (lobeira) por Santos et al. (2002).

Apesar de não terem sido observadas diferenças significativas, a área foliar foi maior nas plantas sob fileiras duplas. Esse fato pode estar associado à disposição oposta cruzada das folhas da carobinha, que embora mais adensadas, aparentemente, isso não resultou em autosombreamento das superfícies de assimilação fotossinteticamente ativas. Esse resultado demonstra que o adensamento das plantas estudado não foi fator limitante para o crescimento da espécie, fato também observado na área de ocorrência nativa, onde as plantas desenvolvem-se reunidas em pequenos grupos, possivelmente ao redor da planta-mãe, dispersora das sementes.

A falta de significância entre arranjos de plantas sobre o diâmetro e o comprimento da maior raiz pode estar associada ao fato de as raízes da carobinha terem se desenvolvido verticalmente no solo. Esse fato é menos comum na área nativa, em que parte do sistema subterrâneo geralmente desenvolvese horizontalmente. Segundo Melo et al. (2008), as plantas lenhosas de Cerrado, além das raízes 
TABELA 1. Área foliar, massa fresca e seca da parte aérea e do sistema subterrâneo, relação massa seca do sistema subterrâneo/massa seca da parte aérea, diâmetro e comprimento da maior raiz da Jacaranda decurrens subsp. symmetrifoliolata cultivada em fileiras simples e duplas, sem (SC) e com (CC) cobertura com cama-defrango, após 555 dias do transplante. Dourados-MS, UFGD, 2008.

\begin{tabular}{|c|c|c|c|c|c|}
\hline \multirow[b]{2}{*}{ Característica } & \multirow[b]{2}{*}{$\begin{array}{l}\text { C.V. } \\
(\%)\end{array}$} & \multicolumn{2}{|c|}{ Número de fileiras } & \multicolumn{2}{|c|}{ Cama-de-frango } \\
\hline & & Simples & Dupla & Sem & Com \\
\hline Área foliar $\left(\mathrm{cm}^{2}\right.$ planta $\left.^{-1}\right)$ & 70,9 & $1302,9 \mathrm{a}$ & $1821,5 \mathrm{a}$ & $1776,3 \mathrm{a}$ & $1548,1 \mathrm{a}$ \\
\hline Massa fresca da parte aérea $\left(\mathrm{kg} \mathrm{ha}^{-1}\right)$ & 76,4 & $1820,8 \mathrm{~b}$ & $4958,1 \mathrm{a}$ & $3312,2 \mathrm{a}$ & $3466,8 \mathrm{a}$ \\
\hline Massa seca da parte aérea $\left(\mathrm{kg} \mathrm{ha}^{-1}\right)$ & 92,5 & $890,5 \mathrm{~b}$ & 2559,6 a & $1616,5 \mathrm{a}$ & $1833,5 \mathrm{a}$ \\
\hline Massa fresca do sistema subterrâneo $\left(\mathrm{kg} \mathrm{ha}^{-1}\right)$ & 51,3 & $2426,4 \mathrm{~b}$ & $6053,1 \mathrm{a}$ & $4629,5 \mathrm{a}$ & $3850,1 \mathrm{a}$ \\
\hline Massa seca do sistema subterrâneo $\left(\mathrm{kg} \mathrm{ha}^{-1}\right)$ & 55,7 & $1134,3 b$ & 2984,7 a & 2206,4 a & $1912,6 \mathrm{a}$ \\
\hline $\begin{array}{l}\text { Relação massa seca do sistema } \\
\text { subterrâneo/massa seca da parte aérea }\end{array}$ & 37,3 & $1,5 \mathrm{a}$ & $1,3 \mathrm{a}$ & $1,5 \mathrm{a}$ & $1,3 \mathrm{a}$ \\
\hline Diâmetro da raiz (mm) & 32,8 & $26,8 \mathrm{a}$ & 29,9 a & $28,1 \mathrm{a}$ & $28,7 \mathrm{a}$ \\
\hline Comprim ento da maior raiz $(\mathrm{cm})$ & 23,7 & $38,1 \mathrm{a}$ & $35,4 \mathrm{a}$ & $37,4 \mathrm{a}$ & $36,2 \mathrm{a}$ \\
\hline
\end{tabular}

Médias seguidas pela mesma letra, nas linhas, para cada variável, não diferem estatisticamente pelo teste $\mathrm{F}$ a $5 \%$ de probabilidade.

profundas, apresentam raízes que se desenvolvem paralelas à superfície do solo e contêm gemas que, com algum estímulo como o fogo, formam novos ramos.

Quanto à ausência do efeito significativo da cama-de-frango sobre as características área foliar, massa fresca e seca da parte aérea e do sistema subterrâneo, relação massa seca do sistema subterrâneo/massa seca da parte aérea, diâmetro e comprimento da maior raiz, esta pode ser justificada pelo fato de o solo de cultivo ter teores consideráveis de fósforo, potássio, cálcio e magnésio quando comparados ao solo de origem, principalmente porque muitas espécies do Cerrado são adaptadas a solos de baixa fertilidade e não respondem à adubação (Melo et al., 2008). Ressalta-se ainda que o sistema radicular desenvolve-se seguindo padrão particular para cada espécie e conforme a estrutura e profundidade do solo onde está sendo cultivada (Larcher, 2000); para a carobinha, sugerem-se estudos posteriores com adubação orgânica (em doses diferentes da estudada) e mineral para certificar a necessidade ou não de nutrientes no cultivo ex situ.

Dessa forma, concluiu-se que o cultivo da carobinha em solo de estrutura física e química diferente daquele do local de origem, possibilitou maior crescimento, independentemente do acréscimo da cama-de-frango como fonte de nutriente e, que o cultivo em fileiras duplas foi favorável à produtividade da carobinha.

\section{AGRADECIMENTO}

À Fundação de Apoio ao Desenvolvimento do Ensino, Ciência e Tecnologia do Estado do Mato
Grosso do Sul (FUNDECT) pela bolsa de doutorado e apoio financeiro concedidos.

\section{REFERÊNCIA}

BATISTINI, A.P. Diversidade morfológica, genética e química de populações naturais de Anemopaegma arvense (Vell.) Stellf. 2006. 83p. Tese (Doutorado) Faculdade de Ciências Agrárias - Universidade Estadual Paulista, Jaboticabal.

BORGES, H.B.N. Estudos sobre demografia de Heteropterys aphrodisiaca O. Mach. (Malpighiaceae): sobrevivência e reprodução no cerrado. Cuiabá: 2002, 29p. (Relatório CNPq/DCR/UFMT).

CARVALHO, J.O.P. Dinâmica de florestas naturais e sua implicação para o manejo florestal. In: CURSO DE MANEJO FLORESTAL SUSTENTÁVEL, 1., 1997, Curitiba. Tópicos em manejo florestal sustentável. Colombo: EMBRAPA-CNPF, 1997. p.43-55. (EMBRAPA-CNPF. Documentos, 34).

COUTINHO, L.M. O bioma do cerrado. In: KLEIN, A.L. (Org.). Eugen Warming e o Cerrado brasileiro: um século depois. São Paulo: Editora UNESP, Imprensa Oficial do Estado, 2002. p.77-91.

FARIAS, R.; PROENÇA, C. Jacaranda decurrens subsp. symmetrifoliolata FARIAS \& PROENÇA (Bignoniaceae), novo táxon para o bioma Cerrado. Boletim do Herbarium Bradeanum, v.11, n.2, p.5-9, 2003.

GUERREIRO, C.P.V.; MING, L.C.; MARCHESE, J.A. Production of aerial and underground biomass of carobinha (Jacaranda decurrens Cham. - Bignoniaceae) at different harvest times. Revista Brasileira de Plantas Medicinais, v.8, n.esp., p.80-2, 2006.

KIEHL, E.J. Adubação orgânica - 500 perguntas e respostas. 2.ed. Piracicaba: Degaspari, 2008. 234p. LARCHER, W. Ecofisiologia vegetal. São Carlos: Rima 
Artes e textos, 2000. 531p.

LEITÃO, A.C.; SILVA, O.A. Variação sazonal de macronutrientes em uma espécie arbórea de cerrado, na Reserva Biológica e Estação Experimental de MogiGuaçu, estado de São Paulo, Brasil. Rodriguésia, v.55, n.84, p.127-36, 2004.

MEDINA, A.F. et al. Determinação da atividade antioxidante e dos teores de flavonóides e fenóis em folhas e raízes de Jacaranda decurrens Cham. ssp. symmetrifoliolata Farias \& Proença cultivada ex situ. In: SIMPÓSIO BRASILEIRO DE PLANTAS MEDICINAIS, 20., INTERNATIONALCONGRESSOF ETHNOPHARMACOLOGY, 10., 2008. Annals and Program... São Paulo: Sociedade Brasileira de Plantas Medicinais, 2008. p.452.

MELO, J.T. et al. Coleta, propagação e desenvolvimento inicial de plantas do cerrado. In: SANO, S.M.; ALMEIDA, S.P.; RIBEIRO, J.F. Cerrado: ecologia e flora. v.1. Brasília: Embrapa Cerrados/Embrapa Informação Tecnológica, 2008. p.321-50.

OLIVEIRA, F.L. et al. Desempenho de taro em função de doses de cama de aviário, sob sistema orgânico de produção. Horticultura Brasileira [online]. v.26, n.2, p.149-53, 2008. Disponível em: <http://www.scielo.br/pdf/ hb/v26n2/04.pdf.> Acesso em: 12 jul. 2008.

PIMENTEL-GOMES, F.; GARCIA, C.H. Estatística aplicada a experimentos agronômicos e florestais exposição com exemplos e orientações para uso de aplicativos. Piracicaba: FEALQ, 2002. 309p.

RIBEIRO JÚNIOR, J.I. Análises estatísticas no SAEG. Viçosa: UFV, 2001. 301p.

ROSA, M.E.C.; NAVES, R.V.; OLIVEIRA JÚNIOR, J.P. Produção e crescimento de mudas de mangabeira (Hancornia speciosa Gomez) em diferentes substratos.
Pesquisa Agropecuária Tropical, v.35, n.2, p.65-70, 2005.

SANGALLI, A.; VIEIRA, M.C.; ZARATE, N.A.H. Levantamento e caracterização de plantas medicinais nativas com propriedades medicinais em fragmentos florestais e de cerrado, em Dourados-MS, numa visão etnobotânica. Acta Horticulturae, n.569, p.173-84, 2002. SANTOS, L.W.; COELHO, M.F.B. Cobertura verde e uso de resíduo orgânico em Lafoensia pacari A.St.- Hil. Revista Brasileira de Plantas Medicinais, v.10, n.3, p.1623, 2008.

SANTOS, M.O. et al. Variabilidade genética entre populações de lobeira (Solanum lycocarpum St. Hil.). Floresta e Ambiente, v.9, n.1, p.158-64, 2002.

SANTOS, R.A.; HERNANDEZ, F.B.; VALÉRIO FILHO, W.V. Estimativa da taxa de crescimento relativo da pupunheira (Bactris gasipaes HBk) a partir de parâmetros climáticos. In: CONGRESSO BRASILEIRO DE ENGENHARIA AGRíCOLA, 33., 2004. São Paulo. Anais... São Paulo: UNESP, 2004. Disponível em <http://www.agr.feis. unesp.br/conbea2004_mineiro1.pdf.> Acesso em: 22 abr. 2008.

SILVA, G.J. et al. Avaliação de plantas adultas de espécies arbóreas do cerrado em função do clima. Revista Agricultura Tropical, v.8, p.43-56, 2006. Disponível em: <www.ufmt.br/agtrop/revista8/doc/04.doc>. Acesso em: 09 mar. 2008.

SOUZA, E.R.B. et al. Emergência e crescimento de plantas de cagaita (Eugenia dysenterica DC.) em diferentes substratos. Revista Brasileira de Fruticultura, v.22, n.3, p.426-30, 2000.

TAIZ, L.;ZEIGER, E. Fisiologia vegetal. 3. ed. Porto Alegre: Artmed, 2004. 719p. 